\title{
Resistencia a vancomicina en aislamientos clínicos de Enterococcus
}

Vancomycin-resistant in clinical isolates of Enterococcus

\section{Señor Editor:}

Enterococcus spp. es un habitante natural del medio ambiente y un componente esencial de la microbiota intestinal de humanos y animales sanos ${ }^{(1,2)}$. Los miembros de este género son patógenos asociados con diversos cuadros clínicos, que incluyen bacteriemia, endocarditis infecciosa, infecciones del tracto urinario $\mathrm{y}$, en casos raros, infecciones del sistema nervioso central $^{(1,2)}$.

Los enterococos se reconocieron como patógenos nosocomiales importantes debido a su resistencia intrínseca a varios antimicrobianos y su capacidad para adquirir rápidamente determinantes de virulencia y resistencia a los antimicrobianos ${ }^{(1,2)}$, entre ellas la resistencia a vancomicina. La infección por Enterococcus resistente a vancomicina (ERV) se asocia con una mayor tasa de mortalidad. La frecuencia de ERV han ido aumentando desde que se encontró por primera vez en $1986^{(1,2)}$. La mayoría de los ERV están asociados con las especies E. faecium (77\%) y E. faecalis (9\%), y el resto representan especies menos frecuentes en infecciones graves, incluidas $E$. gallinarum, E. casseliflavus, E. avium y E. raffinosus $(1,2)$.

Los estudios epidemiológicos sobre ERV demuestran que esta resistencia se debe a la adquisición de genes, principalmente vanA y vanB, los cuales se movilizan a través de plásmidos ${ }^{(1-3)}$. De estos dos genes, el gen van $A$ confiere resistencia a vancomicina y teicoplanina; el gen $\operatorname{van} B$ confiere resistencia variable sólo a vancomicina ${ }^{(1-3)}$.

Nosotros realizamos un estudio con el objetivo de determinar la presencia de resistencia a vancomicina en aislamientos clínicos de enterococos. Entre enero y diciembre de 2017, se colectaron 34 aislamientos consecutivos únicos de ERV (33 de E. faecium y uno de E. faecalis), recuperados de muestras clínicas: sangre, orina, secreciones respiratorias bajas; e hisopados rectales de pacientes hospitalizados en el Instituto Nacional de Enfermedades Neoplásicas (INEN) del Perú (tabla 1). La identificación y susceptibilidad antimicrobiana, se realizó por el sistema automatizado Phoenix (BD Diagnostics, Sparks, MD). La caracterización molecular para identificar la presencia de genes asociados a resistencia se realizó mediante PCR ${ }^{(4)}$

Prácticamente todos los aislamientos de Enterococcus spp. mostraron resistencia a glucopéptidos (sólo dos aislamientos presentaron susceptibilidad intermedia a teicoplanina), además de ser resistentes a ampicilina y eritromicina. Adicionalmente, presentaron sensibilidad a gentamicina $22 / 34(64,7 \%)$ y ciprofloxacino $3 / 34$

Tabla 1. Distribución de aislamientos de Enterococcus spp. resistentes a vancomicina según tipo de muestra y procedencia.

\begin{tabular}{lcccc}
\hline \multirow{2}{*}{ Procedencia } & \multicolumn{4}{c}{ Tipo de muestra } \\
\cline { 2 - 5 } & Sangre & Orina & $\begin{array}{c}\text { Secreciones } \\
\text { respiratorias bajas }\end{array}$ & $\begin{array}{c}\text { Hisopados } \\
\text { rectales }\end{array}$ \\
\hline Medicina oncológica & 8 & 3 & 2 & 15 \\
Pediatría oncológica & 4 & -- & -- & - \\
Urología & 1 & 1 & -- & - \\
Trasplante de médula ósea & -- & -- & -- & 1 \\
TOTAL & 13 & 4 & 2 & 16 \\
\hline
\end{tabular}


$(8,8 \%)$. Se observó un solo aislamiento con resistencia a linezolid. La presencia del gen vanA se detectó en 29/34 (85,2\%) de los aislamientos de ERV.

En Latinoamérica, la resistencia a glucopéptidos en Enterococcus spp. está mediada por el gen vanA, mostrando además una marcada multi resistencia, quedando como alternativa terapéutica linezolid, como se ha descrito en la mayoría de los países de la región ${ }^{(4,5)}$. La presencia de ERV portador del gen van $A$ ya fue notificada en casos de infección y colonización intestinal en Perú ${ }^{(3-5)}$.

Una de las limitaciones de nuestro estudio fue que no se analizaron otros genes de resistencia a vancomicina diferentes a vanA y vanB. Además, siendo necesaria la caracterización molecular que nos permita conocer el entorno y las plataformas genéticas donde se movilizan estos genes.

En conclusión, ERV productor de vanA está presente en el INEN. El gen vanA, al encontrarse en elementos móviles, podría ser transmitido a otras bacterias más patógenas, ocasionando por ejemplo, la aparición de Staphylococcus aureus resistente a vancomicina. En ese sentido, un enfoque de epidemiología molecular es importante para desarrollar estrategias de control y manejo de este tipo de microorganismos en nuestro país.

\section{Katherine Yauri-Condor ${ }^{1, a}$ (iD, Milagros Zavaleta Apestegui ${ }^{1, b}$ (iD, Carlos Raúl Sevilla-Andrade ${ }^{1,2, c}$ (iD), Julia Piscoya Sara ${ }^{2, d}$ (iD, William Vicente Taboada ${ }^{3,4, e}$ iD, Edgar Gonzales-Escalante ${ }^{1,5, f}$ (iD}

\section{Correspondencia:}

Edgar Gonzales Escalante

Correo electrónico: egones5@gmail.com

\section{REFERENCIAS BIBLIOGRÁFICAS}

1. Ahmed MO, Baptiste KE. Vancomycin-Resistant Enterococci: A review of antimicrobial resistance mechanisms and perspectives of human and animal health. Microb Drug Resist. 2018; 24(5):590-606. doi: $10.1089 / \mathrm{mdr} .2017 .0147$

2. Faron ML, Ledeboer NA, Buchan BW. Resistance mechanisms, epidemiology, and approaches to screening for vancomycin-resistant Enterococcus in the health care setting. J Clin Microbiol. 2016; 54(10):2436-2447. doi:10.1128/JCM.00211-16.

3. Estrada-Roman A, Mendo-Lopez R, Astocondor L, Zervos M, Garcia C. Colonización por enterococo resistente a vancomicina en pacientes internados de un hospital de Lima, Perú. Rev Peru Med Exp Salud Publica. 2017; 34(4):666-71. doi: 10.17843/ rpmesp.2017.344.2617

4. Panesso D, Reyes J, Rincón S, et al. Molecular epidemiology of vancomycin-resistant Enterococcus faecium: a prospective, multicenter study in South American hospitals. J Clin Microbiol. 2010; 48(5):1562-9. doi: 10.1128/JCM.02526-09.

5. Rios R, Reyes J, Carvajal LP, et al. Genomic Epidemiology of Vancomycin-Resistant Enterococcus faecium (VREfm) in Latin America: Revisiting the Global VRE Population Structure. Sci Rep. 2020; 10(1):5636. doi: 10.1038/s41598-020-62371-7.

Recibido: 07/10/2021

Aceptado: 25/10/2021

\footnotetext{
Centro de Investigaciones Tecnológicas, Biomédicas y Medioambientales, Universidad Nacional Mayor de San Marcos. Lima, Perú.

2 Instituto de Medicina Tropical "Daniel A. Carrión", Departamento Académico de Microbiología Médica, Facultad de Medicina, Universidad Nacional Mayor de San Marcos. Lima, Perú.

3 Instituto Nacional de Enfermedades Neoplásicas. Lima, Perú.

4 Laboratorios Unilabs. Lima, Perú.

5 Laboratorio de Resistencia Bacteriana, Instituto de Investigaciones en Bacteriología y Virología Molecular, Facultad de Farmacia y Bioquímica Universidad de Buenos Aires. Buenos Aires, Argentina.

a Tecnólogo Médico.

b Biólogo molecular,

Tecnólogo Médico.

d Médico cirujano; Magister en Epidemiología.

- Patólogo clínico.

f Tecnólogo Médico; Magister en Microbiología.
} 